\title{
Simulation Of Fuzzy Based M3C- UPQC For Power Quality Improvement In Power Grid
}

\author{
M.Ankarao, Mathaku Sandya Rani
}

\begin{abstract}
Power quality improvement is very much crucial due to the recent advancements in the equipments at consumer end, which mainly contains the power electronic equipments responsible for the nonlinearities in voltage and current at the load end of the distribution system. For suppressing these nonlinearities an equipment is proposed to have a feature of hybrid compensating system property to reduce both voltage and current disturbances. Which contains series and shunt active power filter combination. Series active power filter is used to suppress voltage disturbance by injecting voltage into the system, and shunt active power filter is used to reduce current disturbance by injecting current into the system. Many topologies and many control strategies are proposed for particular system behaviour. Analysis of equivalent circuit for modular matrix multilevel circuit control strategy incorporates integrated control method comprised of internal balance and external compensation, involves inter and intra capacitive voltage divergence balance through circulating current, A fuzzy logic based M3C UPQC is proposed to improve THD performance of the system. The effectiveness of fuzzy logic controller is examined by MATLAB/SIMULINK software.
\end{abstract}

Index Terms - Fuzzy Logic Controller, Modular Matrix Multilevel Converter, UPQC.

\section{INTRODUCTION}

In recent advancements in the equipments used in power system network the quality of power supplied to the consumers used is very important for this purpose the voltage and current characteristics at the load terminals should be ideal without any distortions from the grid side voltage and current value for this purpose a suitable equipment is used which is used to control the voltage and current disturbances in the power system network is named after UPQC which is explained as series and shunt active power filter combination in[1].Based on configuration involved in power system and based on approaches involved in compensation of voltage disturbances UPQC systems are classified into different types modular, multilevel, left, right, interline, multi converter, $\mathrm{P}$, $\mathrm{Q}$, combined UPQC and distributed generators integrated with UPQC all are discussed in [2].In order to eliminate the disadvantages due to hard switching in UPQC system a soft switching technology is implemented and its detailed description is presented in [3].Different cascaded multilevel converter UPQC along with modular and matrix topologies and their advantages are discussed in [4].Cascaded multilevel inverter based UPQC performance is studied based on synchronous reference frame theory and voltage harmonic distortion values is studied in[5].And also discussed about cascaded multilevel converter control strategies for getting

M.ANKARAO, EEE, JNTUACEA, Ananthapuramu, INDIA, 7702968080

MATHAKU SANDYA RANI, EEE , JNTUACEA, Ananthapuramu, INDIA, 9160986760 more smooth waveform is explained in [6].And a new UPQC topology without a series injection transformer for medium and high voltage distribution systems is discussed in [7].And circulating current control scheme of modular multilevel converter UPQC is studied in [8].And converter inner circuit parameter control and capacitive voltage balance system UPQC is discussed in [9].And a second order integrator based phase locked loop is presented in[10].

\section{UPQC STRUCTURE AND EQUIVALENT CIRCUIT:}

\section{A. Topological Structure Of M3C UPQC:}

Structure of M3C UPQC contains series and parallel back to back combination of voltage source converters. The main aim involved here is to give good quality of power supply to the consumer end. For this purpose the power quality disturbance terms current distortions and voltage disturbances rectified by compensating device with proper control strategy. Series converter control structure is used to rectify the voltage sag and swells and shunt converter structure is used to rectify current harmonic distortions due to nonlinear loads. By using this M3C strategy is used to increase the gain value of the output voltage by using modulation index value and the multilevel converter circuit concept is used to decrease the switching losses of the circuit by increasing the number of switching circuit levels. There by obtaining the more smoothen waveform and many control strategies are employed for particular purpose of the consumer premises. The schematic diagram of single phase M3C-UPQC is shown in below Fig 1.

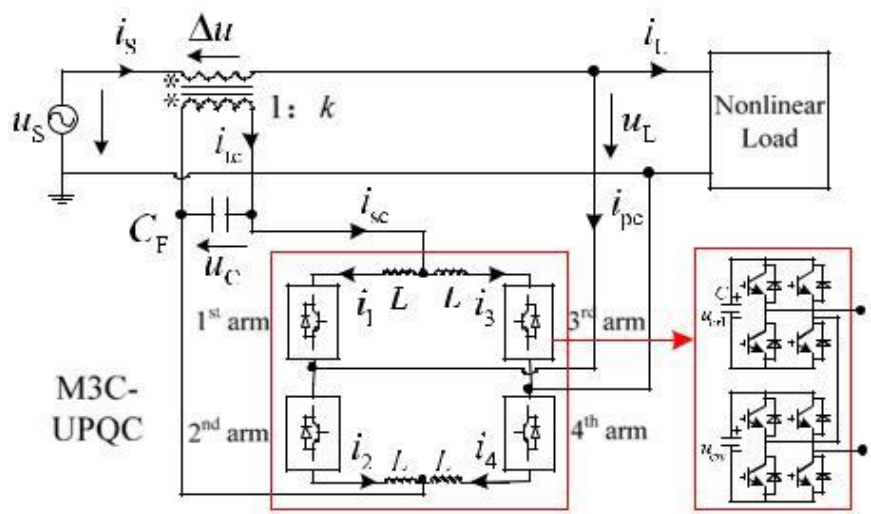

Fig 1.Schematic diag Of Single Phase UPQC.

In this M3C UPQC structure involves four multilevel converter arms and four filtering inductors and a dc link capacitor. This UPQC structure is placed in between the source and load for suppressing disturbance due to frequent non linear creating loads. Due to multilevel converter circuit involved it can be possible to used for high voltage power grid. 


\section{B. Equivalent Circuit Description:}

According to the fig.1 represent four arm UPQC used for power quality improvement in distribution system mentioned about the terms $i_{s c}$ and $i_{p e}$ which represents about series current and parallel current of the four arm circuit.And $i_{z}$ which is circulating current which has no effect on the output current of the power system network. The main aim here is to decouple the system into Dc and Ac equivalents for proper improvement in the quality of power in power system network. By controlling the dc equivalent by without effecting the ac equivalent we have to achieve the active power balance of the circuit. Let us considering the equivalent circuit equations involved for the analysis purpose are containing $i_{x}(x=1,2,3,4)$ which are arm currents of UPQC circuit and $i_{z}$ is The circulating current involved. $u_{1}, u_{2}, u_{2}$ and $u_{4}$ are the individual arm voltages. The equivalent circuit of control circuit is described in Fig 2

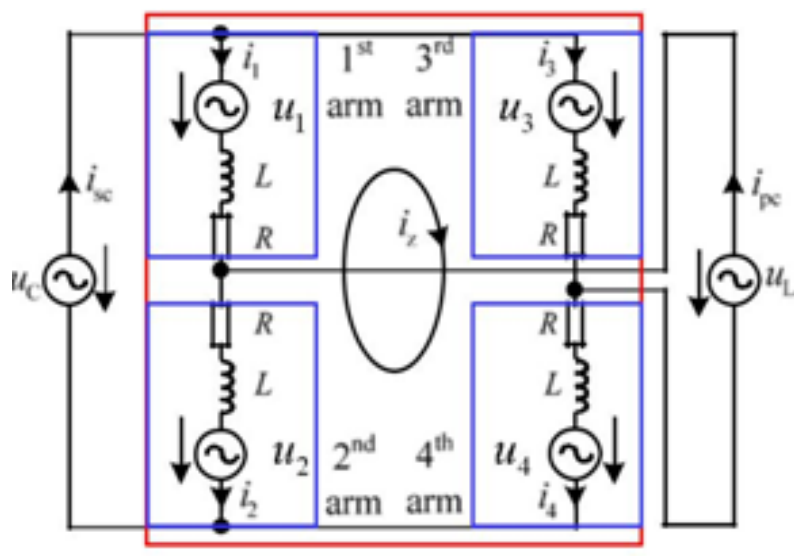

Fig 2.Equivalent circuit

Series, shunt branch as

$$
\begin{aligned}
& i_{g c}=i_{1}+i_{a}=i_{2}+i_{4} \\
& i_{p e}=i_{2}-i_{1}=i_{a}-i_{4} \\
& i_{z}=\frac{\left(i_{3}+i_{4}-i_{2}-i_{1}\right)}{4}
\end{aligned}
$$

Individual voltages of each arm can be expressed as dc and ac equivalent configurations as below.

$$
\begin{aligned}
& u_{4,1}=v_{g 1}+u_{z 1}=\frac{u_{c}-w_{L}}{2}-\frac{L}{2} \frac{\alpha\left(I_{s c}-l_{p c}\right)}{d t}-R\left(i_{s c}-i_{p c}\right) \pm u_{z 1} \\
& u_{2, a}=v_{g 2}+u_{z 2}=\frac{w_{c}+w_{L}}{2}-\frac{L}{2} \frac{\alpha\left(I_{s c}+1_{p c}\right)}{d t}-R\left(i_{g c}+i_{p c}\right) \pm u_{z 2}
\end{aligned}
$$

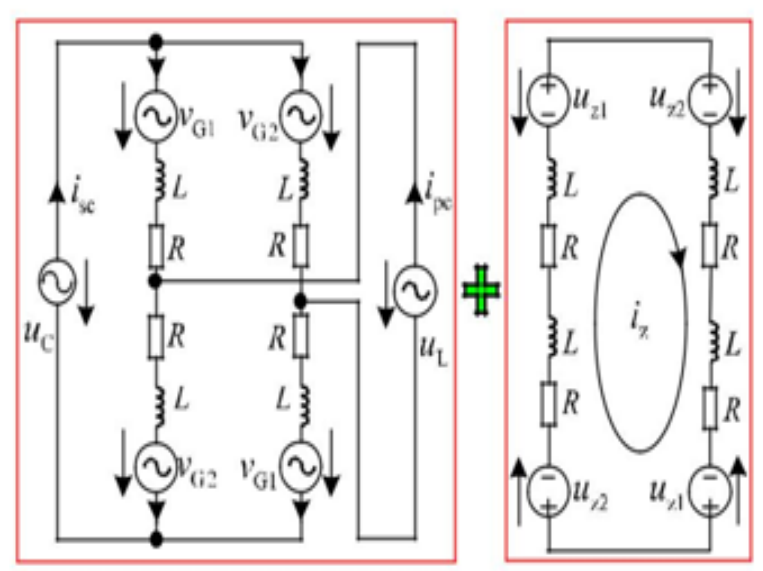

Fig 3. Decoupled circuit.

\section{INTEGRATED CONTROL METHOD:}
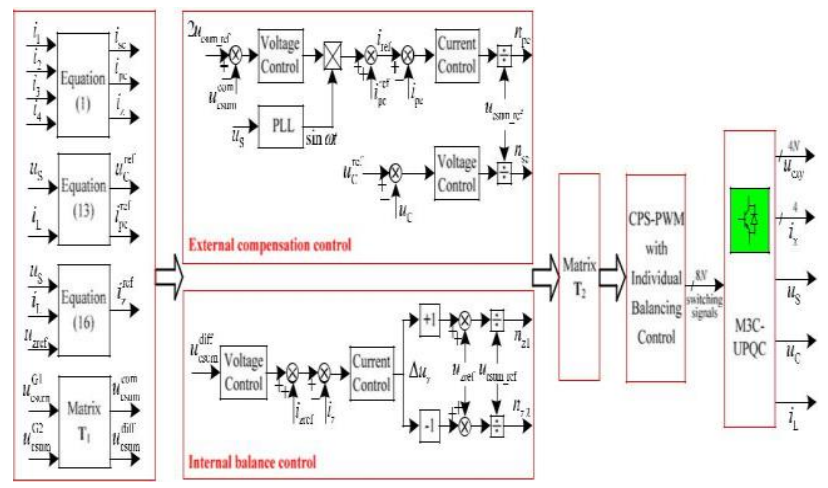

Fig.4 control circuit.

In this integrated control strategy resolved into two sub groups as internal balance and external compensation control. These in detail can be discussed as below.

\section{A. Internal Balance Control:}

Internal balancing control is used to balance the internal capacitive voltage this MMC topology having an additional freedom to balance the capacitive voltage by using circulating current. The main purpose involved here is to balance the active power transfer in between the converter arms without affecting the external compensation of the overall circuit. The differential voltage will be used to achieve the active power balance in between the arm groups of M3C UPQC. In internal balancing control for overall power quality we have to use two PI controllers for differential voltage compensation and circulating current compensation. By injecting proper injected voltages to the two arm groups as $u_{z 1}$ and $u_{z 2}$ this values can be obtained by adding $\Delta u_{z}$ to the $u_{z \text { zref }}$ and $i_{\text {zref }}$ to the current controller.

\section{B. External Compensation Control:}

External compensation is responsible for the total power stabilisation through compensation of voltage and current for this purpose we have to consider the equations concerning summed capacitive voltage and shunt currents. Capacitive voltages represented by common mode voltages and circulating current represented by differential mode voltages. As mentioned earlier the equivalent circuit of M3C UPQC involves two groups in positive and negative cycles. The relation between the common mode and differential mode can be represented by a transformation matrix. The synchronisation in between the grid side and load side can be achieved by a PLL. The phase locked loop described above is a second order integrator based phase locked loop. The dual control described above is current control and voltage control uses two PI controllers one is for current control and another is for voltage control and another tolerated tracking error

\section{IV. .M3C UPQC USING FUZZY LOGIC CONTROLLER:}

Fuzzy logic controller operation is quick easy and low cost process for obtaining desired values of output from the quantities whose analysis process through the nonlinear circuits is quiet complex This fuzzy logic controller circuit contains no of input variables for getting single output or multiple outputs in accordance with the requirement.In this 
error in voltage $\mathrm{V}$ and change in votage error $\Delta V$ are the input variables for getting output voltage.Here in this analysis purpose FIVE linguistic variables are adapted and 25 rules are framed.The respective table concerning the fuzzy rule base can be given below. Here in this mamdani model triangular membership functions are used for obtaining the desired output value. In this fuzzy logic controller circuit the range of values of the error in voltage and change in error numerical values are framed into five linguistic variables and these are by framing rules are converted into crisp values.

TABLE 1 :Fuzzy Rule Base Table

\begin{tabular}{|l|l|l|l|l|l|}
\hline$v$ & VS & $\mathbf{S}$ & $\mathbf{M}$ & $\mathbf{L}$ & VL \\
\hline VS & VS & VS & S & M & M \\
\hline $\mathbf{S}$ & VS & S & S & M & L \\
\hline M & VS & M & M & L & L \\
\hline L & M & L & M & L & VL \\
\hline VL & M & L & L & L & VL \\
\hline
\end{tabular}

V. SIMULINK DIAGRAM OF M3C UPQC:

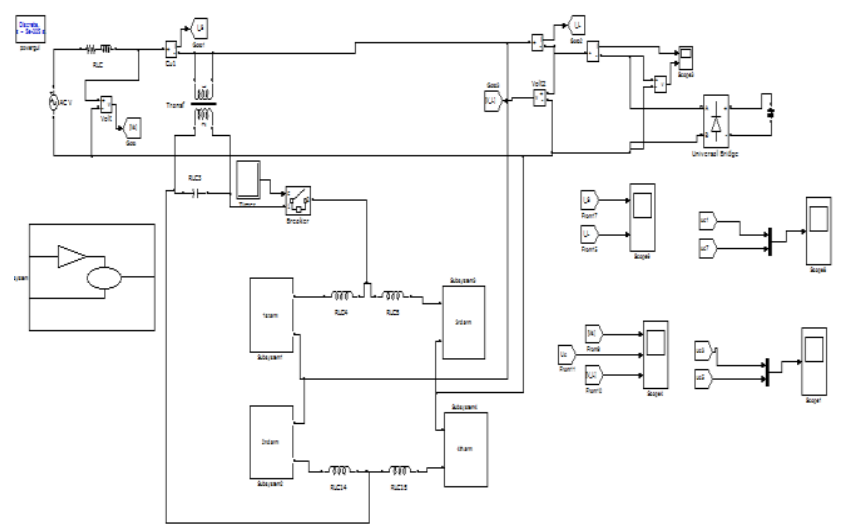

Fig.6 Simulink diagram of M3C UPQC. Simulation Results:
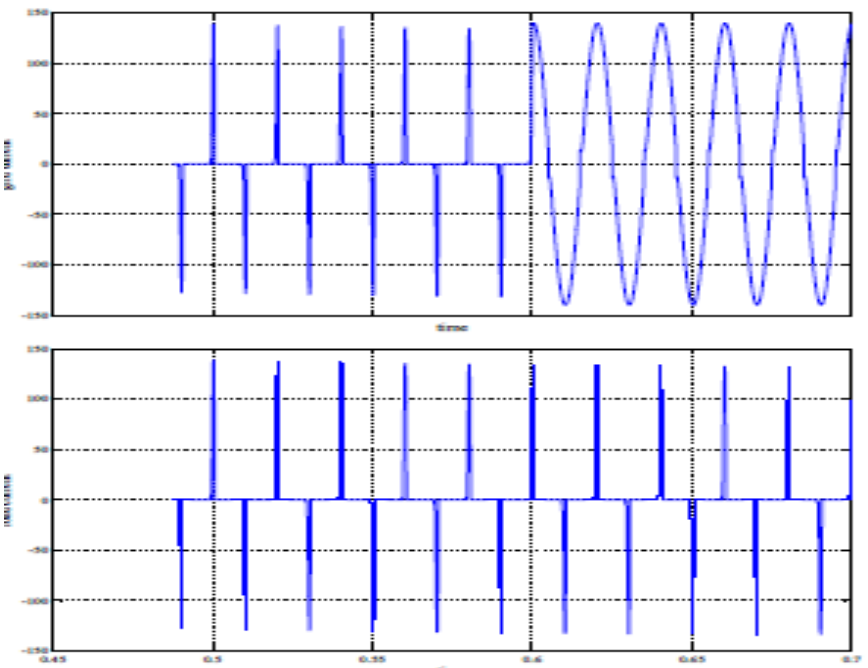

Fig.7 (a) grid current, (b) shunt current


Fig. 8(a)grid voltage (b)capacitor voltage and (c) load voltage.



Fig.9 positive arm group capacitor voltage.

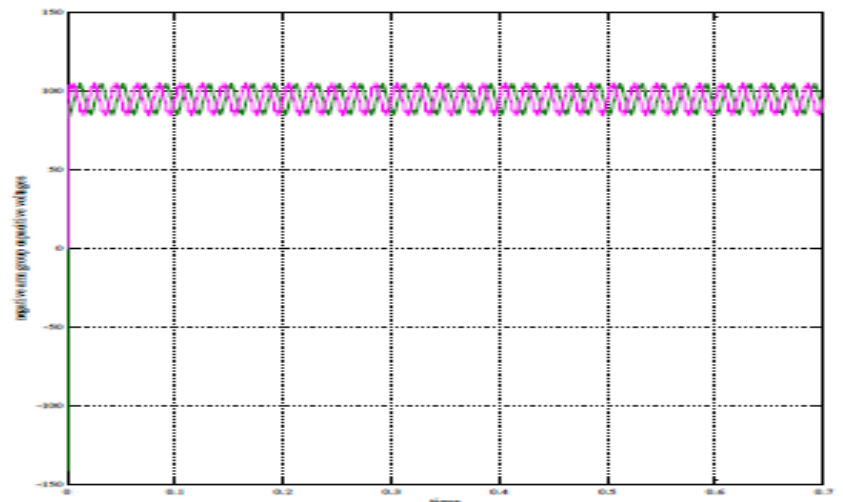

Fig.10 negative arm group capacitor voltage.
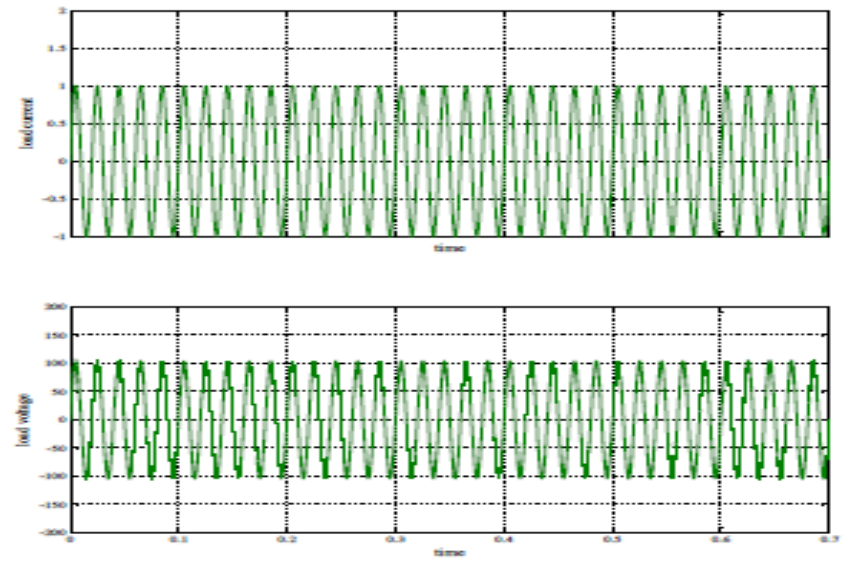

Fig.11 (a) load current (b) load voltage. 
FFT analysis for M3C UPQC:

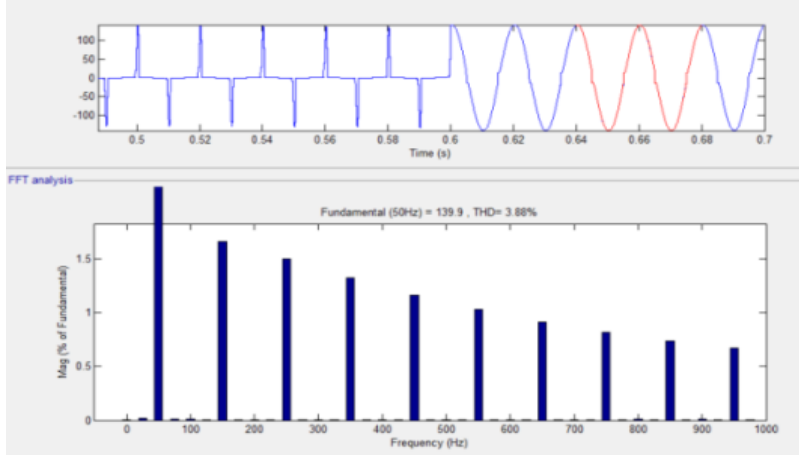

Fig.12 grid current FFT analysis waveforms.

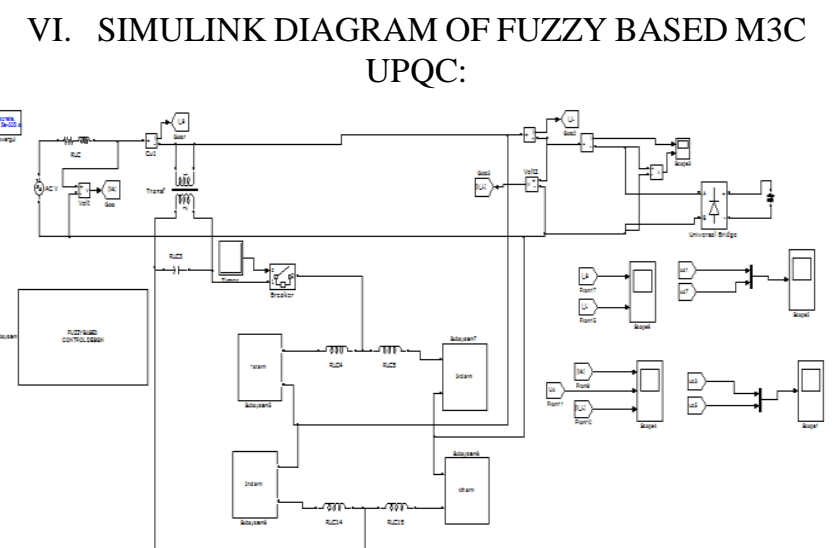

Fig. 13 simulink diagram of fuzzy based M3C UPQC. Simulation results:
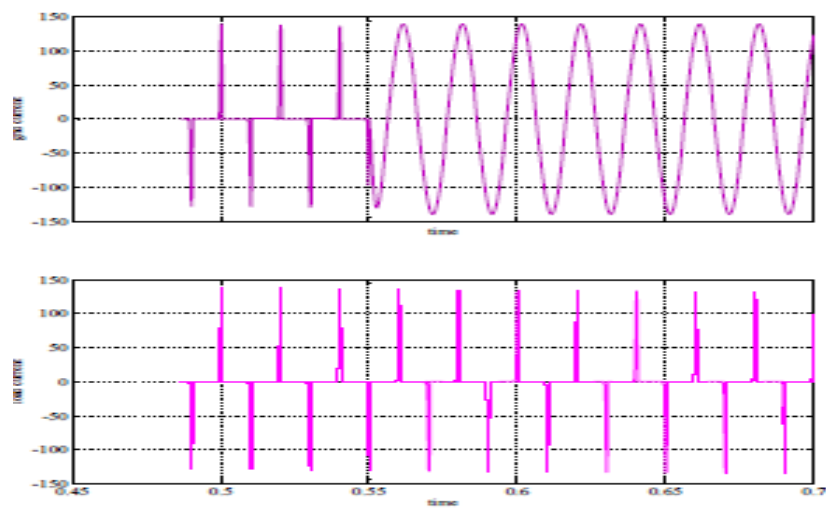

Fig.14 (a) grid current (b) shunt current
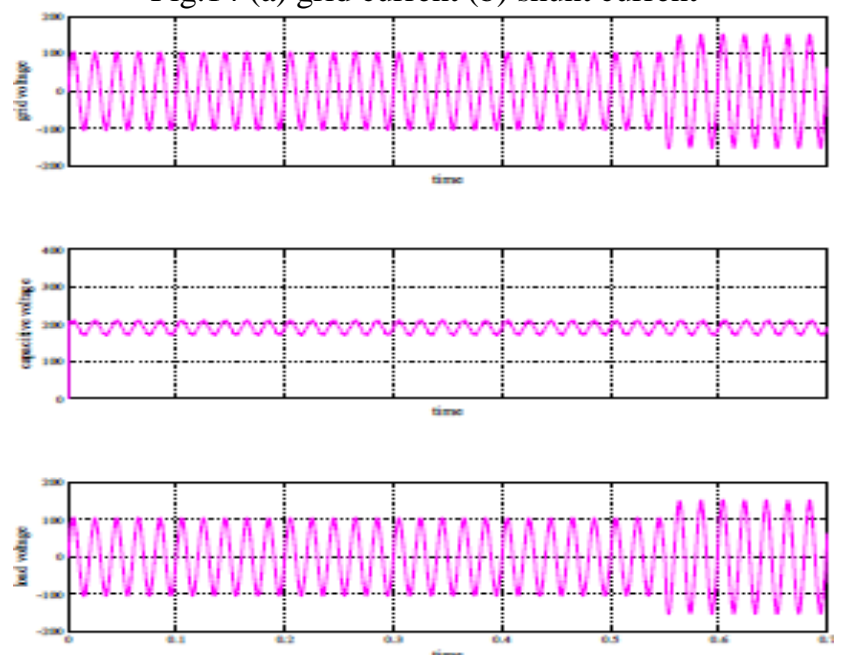

Fig.15 (a) grid voltage (b) capacitor voltage (c) load voltage

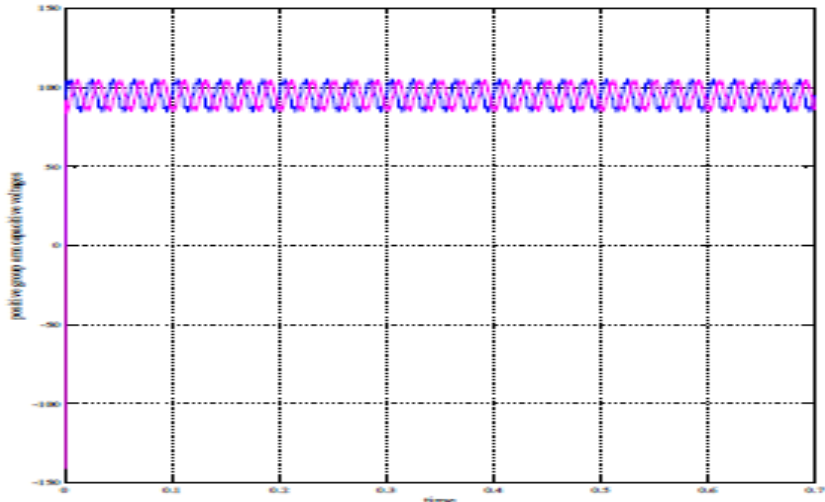

Fig.16 positive arm group capacitor voltage.

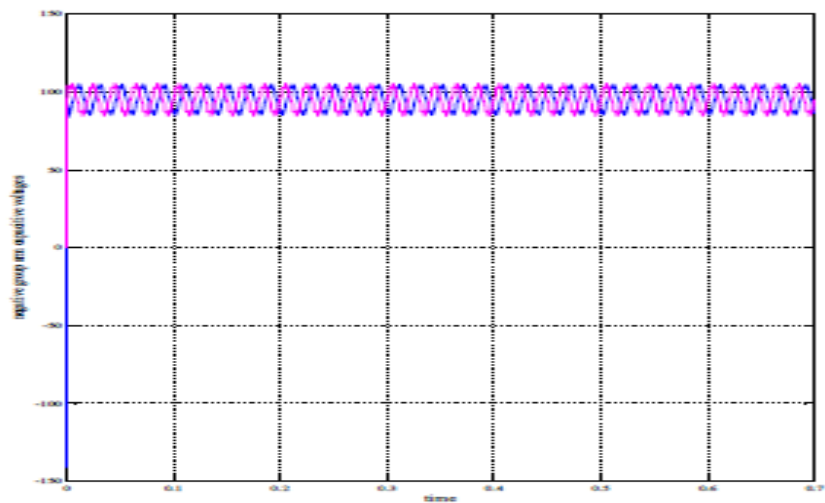

Fig.17 negative arm group capacitor voltage.
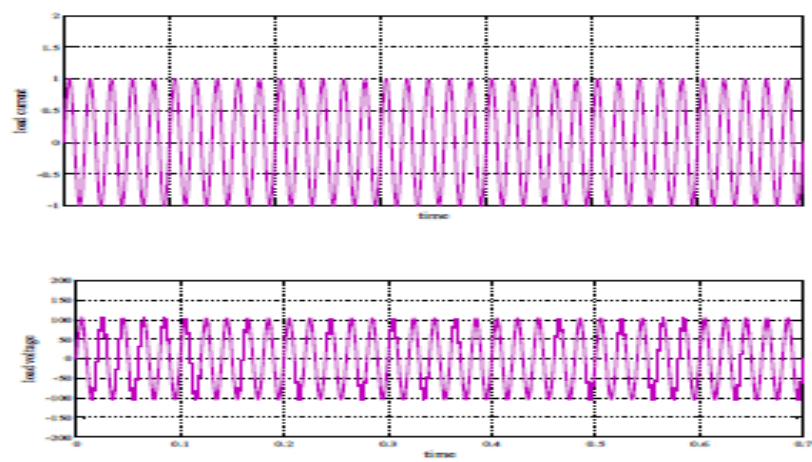

Fig.18 (a) load current and (b) load voltage.

FFT analysis of FUZZY based M3C UPQC:

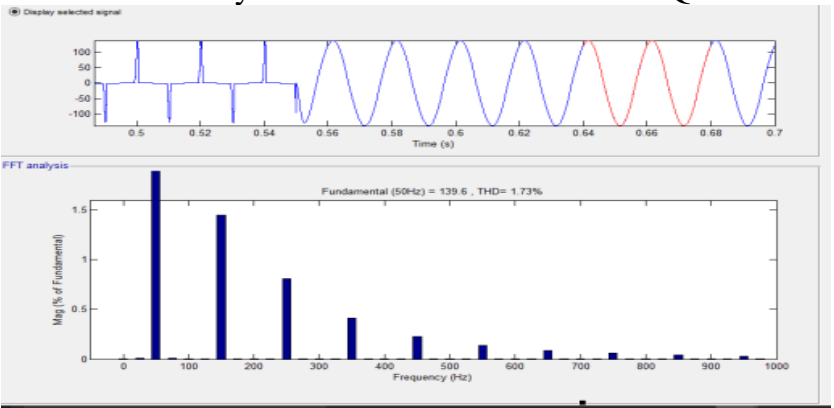

Fig.19 grid current FFT analysis waveforms.

VII. CONCLUSION:

In this paper, Single phase M3C based UPQC with integrated control strategy is discussed. In this control scheme active power balance can be achieved by inter and intra arm capacitive voltage balance through circulating current. The proposed Fuzzy Logic Controller based M3C UPQC is also discussed, which includes fuzzy logic controller in the place 
of PI controller of the conventional M3C UPQC, used to improve the THD value of grid current disturbance from $3.88 \%$ to $1.73 \%$ concludes improved power quality of distribution system network.

\section{ACKNOWLEDGMENT}

I wish to thank Sri. M. ANKARAO ${ }_{\text {M.Tech., }(\mathrm{PhD}) \text {,Assistant }}$ professor in dept. of EEE, JNTUA College of Engineering\& technology, Ananthapuramu for his valuable guidelines throughout my project work and extended his support for the success of this project. I take this opportunity to convey my sincere thanks to my parents, friends and to all those who have directly and indirectly contributed for the successful completion of my project.

\section{VIII.REFERENCES:}

[1] H. Fujita and H. Akagi, "The unified power quality conditioner: the integration of series- and shunt-active filters," IEEE Trans. Power Electron, vol. 13, no. 2, pp. 315-322, Mar. 1998.

[2] V. Khadkikar, "Enhancing electric power quality using UPQC: a comprehensive Overview," IEEE Trans. Power Electron., vol. 27, no. 5, pp. 2284-2297, May 2012.

[3] M.-C. Jiang, K.-C. Chang, K.-Y. Lu, B.-J. Shih, and T.-C. Liu, "A softswitching single-phase unified power quality conditioner," in Proc. Int. Power Electron. Conf., 2014, pp. 105-109.

[4] K. Ilves, L. Bessegato, and S. Norrga, "Comparison of cascaded multilevel converter topologies for AC/AC conversion," in Proc. Int. Power Electron. Conf., 2014, pp. 1087-1094.

[5] V. N. Chellammal and R. Abirami, "Power quality conditioning using hybrid multilevel inverter as UPQC," in Proc. 2013 Int. Conf. Circuits, Power Comput. Technol., 2013, pp. 43-48.

[6] M. Ayslan, C. N. Jacobina, C. B. Carlos, and A. A. Gregory, "A new three-phase AC-DC-AC multilevel converter based on cascaded threelegconverters," in Proc. IEEE Energy Convers. Congr. Expo., 2015, pp. 4685-4692.

[7] B. Han, B. Bae, S. Baek, and G. Jang, "New configuration of UPQC for medium-voltage application," IEEE Trans. Power Del., vol. 21, no. 3 , pp. 1438-1444, Jul. 2006.

[8] W. Hao, M. Guihua, L. Jinjun, and L. Fangcheng, "A circulating current suppressing control in modular multilevel converter based unified power quality conditioner," in Proc. IEEE ECCE Asia Downunder, 2013, pp. 716-720.

[9] M. Vasiladiotis, N. Cherix, and A. Rufer, "Single-to-three-phase direct AC/AC modular multilevel converters with integrated split battery energy storage for railway interties," in Proc. 17th Eur. Conf. Power Electron. Appl., 2015, pp. 1-7.

[10] M. Ciobotaru, R. Teodorescu, and F. Blaabjerg, "A new single-phase PLL structure based on a second order generalized integrator," in Proc. IEEEPower Electron. Spec. Conf., Jun. 2006, pp. 1-6.



M.Ankarao received the B.E.degree in electrical engineering from the Andhra university, India, in 2006, the M.Tech.degree in Power And Industrial Drives from Jawaharlal

NehruTechnologicalUniversity,Ananthapuramu, India, in 2010, and pursuing the Ph.D.degree in electrical engineering from Jawaharlal Nehru Technological University, Ananthapuramu and working as an Assistant Professor in Jawaharlal Nehru Technological University, Ananthapuramu.

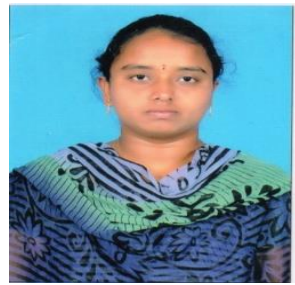

Mathaku Sandya Rani received the B.E degree in electrical and electronics engineering from the Jawaharlal Nehru Technological University, Ananthapuramu, India, in 2015 ,currently pursuing the M.Tech. degree in power and industrial drives(PID) in the Jawaharlal Nehru Technological University, Ananthapuramu. 